\title{
WATER SOLUTIONS THAT MEET THE NEEDS OF PEOPLE AND NATURE
}

\section{ENVIRONMENT PROGRAM REFLECTION}

The S. D. Bechtel, Jr. Foundation envisions a California that manages, stewards, and conserves its water and land to support a resilient environment and healthy communities. As the Foundation approaches conclusion in 2020, staff are documenting strategies from priority program portfolios. Access the series of Foundation reflections at sdbjrfoundation.org.

\section{OVERVIEW}

California's water system supports nearly 40 million people, the world's fifth largest economy, diverse natural ecosystems, and one of the most productive agricultural regions in the world. Yet this critical system is under significant stress: Californians face increased water scarcity, declining water quality, greater flood risk, and the deteriorating health of ecosystems.

Promising solutions exist, and there are many examples of innovation and collaboration to address the state's water challenges. However, the speed and scale of change are often limited by a lack of cohesion in practices, fragmented institutions, complex technical challenges, under-resourced nonprofits, and the lack of political will. In this context, between 2009 and 2020, the S. D. Bechtel, Jr. Foundation awarded more than \$130 million in program funds to support California's transition to a more sustainable water future.

Grants were orchestrated within three interconnected strategies: building knowledge to improve decisions, pursuing integrated solutions to complex challenges, and engaging more funders. These strategies spurred progress on interrelated goals involving groundwater management, flood protection, stormwater and urban resilience, drinking water quality, and open data. Foundation grants also helped bring forward billions of dollars in new public funding as well as $\$ 80$ million in new philanthropic capital.

Milestones achieved are transforming how California manages water. This impact was the product of difficult, dedicated effort by many individuals, organizations, and coalitions committed to change. Their progress was aided by public attention and desire for solutions emanating from an historic, extreme drought. Their work was supported by flexible risk capital and capacity-building outlays for the water field provided by philanthropy.

This brief further describes the primary strategies, outcomes, and takeaways from the Foundation's water program. While drawn from one grantmaker's experience in California, this content can have broad relevance to practitioners, policymakers, and funders everywhere who seek a secure water future for people and nature.

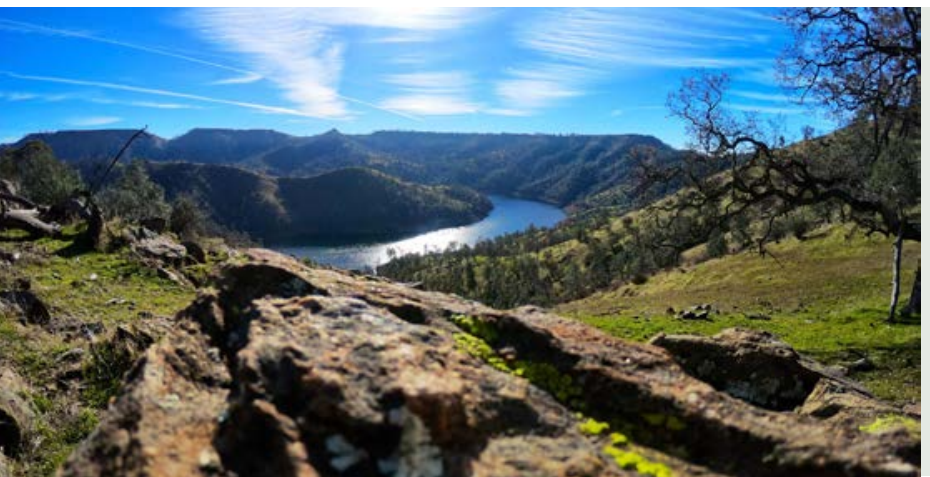

The Foundation collaborated with

dedicated, thoughtful grantees and partners who worked to find and support solutions to the water challenges that confront California and the American West. 


\section{WHY WATER?}

People are affected by water every day, in more ways than most realize. Water, or lack thereof, creates conditions for public health, food production, habitat, city streets, recreation, housing, wildfires, and so much else. Addressing water's impact on communities is especially important as society confronts climate change and growing inequities that lead to too much water, not enough water, and poor water quality. Water will always be essential to productive, vibrant, and sustainable places - and effective water management is especially urgent, and challenging, in California and the western United States.

Philanthropy has been less engaged with water compared to other issues. Some funders acknowledge water's importance but question whether it has a sufficiently direct link to topics they consider priorities. Some see the system that produces water decisions as difficult to change - with entrenched power brokers and polarized constituencies. Others view water as primarily a local concern that precludes large-scale improvement.

In 2009, the S. D. Bechtel, Jr. Foundation decided to spend down all assets and water was named a key program area because of its importance to California. This decision was informed and inspired by the work of the California Conservation Fund. The California Conservation Fund was a charitable operating foundation established by Stephen D. Bechtel, Jr. to protect and restore waterfowl habitat. Its programs resulted in conservation of more than 4,000 acres of prime habitat for native species and provided insight into the underlying dynamics of wetland and open space management. With land and water holdings in Kern County and elsewhere, Fund leaders navigated California's complex water system, earning knowledge and relationships along the way. This experience helped the Foundation's board and staff accrue appreciation for the hydrological, economic, social, and political factors driving water management statewide.

The choice to focus on water was bolstered with the optimism and resolve required to work on seemingly intractable issues. Foundation leaders felt strongly that change was possible and that major investments were well worth making, even if success was not guaranteed. Mr. Bechtel was at the forefront of this commitment; he took a hands-on role in the field scan and strategy development that set direction for the water program.
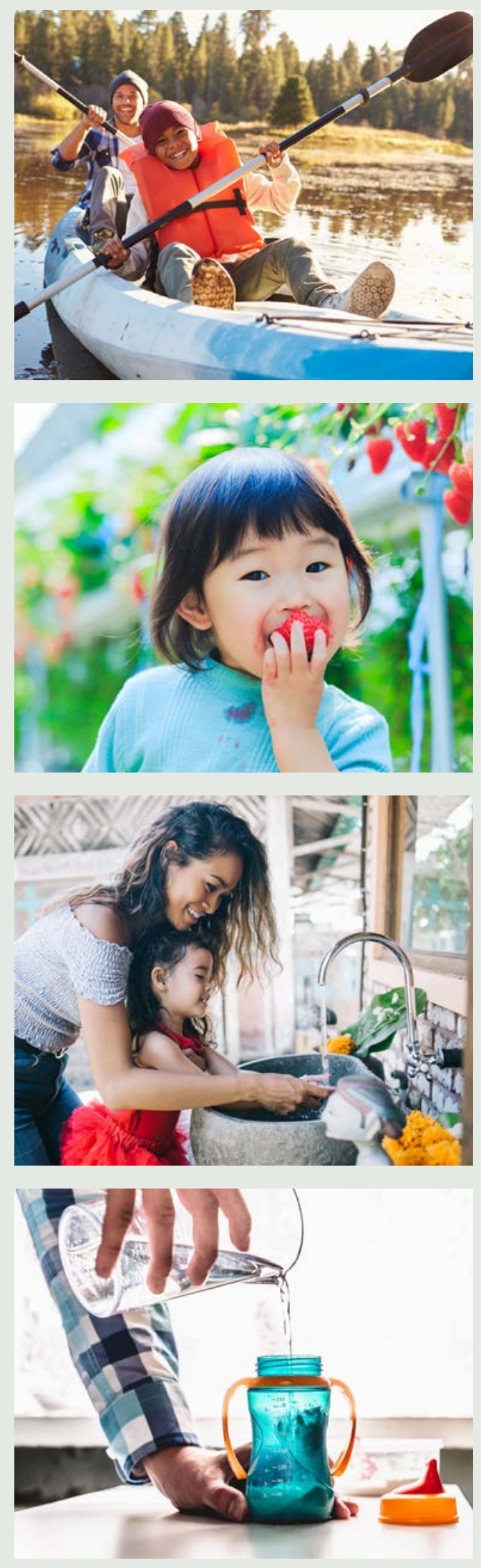


\section{THE WATER PROGRAM}

California water reflects a paradox of place and time. Most of the state's water falls to the north, while a majority of its population lives in the south. Most water arrives in the winter as snow or rain, but people and agriculture need more water in the summer. Some years there is too much water, other years too little. To account for these hydrologic realities and negative impacts, California built a web of institutions and infrastructure to store, move, treat, and deliver water across regions, seasons, and years. These entities and support systems are dedicated to meeting the state's needs, but they are inadequate to the demands they encounter. As a result, water scarcity is increasing, water quality is declining, flood risks are growing, and the health of ecosystems is deteriorating.

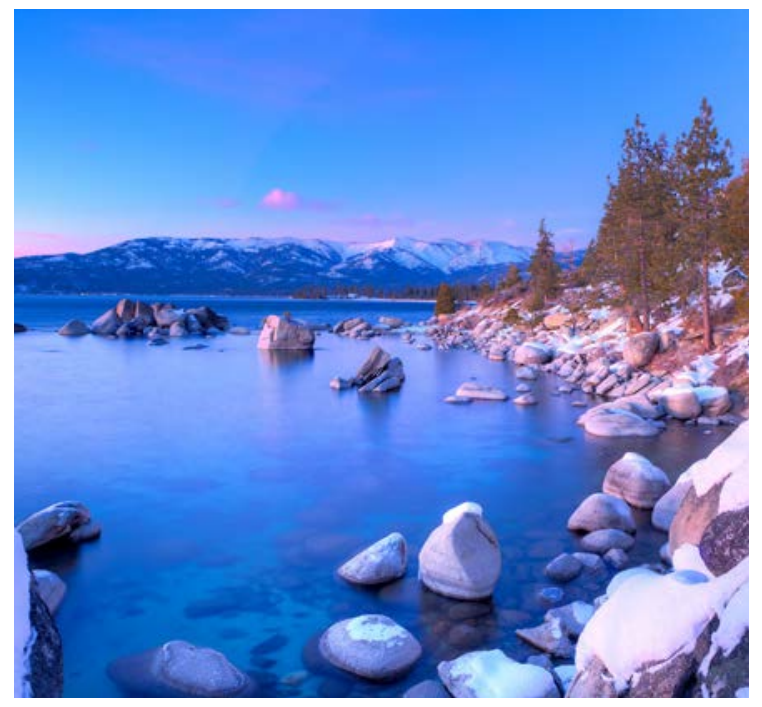

The Foundation's water program was rooted in a core belief that California can manage its water to meet the needs of people and nature - but only if these needs are considered together and only if management strategies jointly address surface water, groundwater, water quality, and flood protection challenges. The Foundation committed to this integrated water management approach (also known by proponents as "sustainable water management," "one water," or "one watershed"). It awarded grants to organizations and initiatives through three linked strategies: building scientific knowledge to improve decision-making; pursuing policies that support integrated solutions - including demonstrating solutions at regional scale; and engaging more funders in water issues.

"There isn't an obvious or simple approach to improving water management," stated Laurie Dachs, the Foundation's president. "It required us to work the problem - define it, try something, learn, and try again." Foundation strategies were informed by a wide range of water experts. At the outset, the Foundation sought to learn as much as possible about water, quickly, and entered into dialogue that continued for the duration of the water program. Staff regularly attended meetings, workshops, and conferences with the goal of listening to the field. They also convened ad hoc advisory councils to guide specific projects. Through this process the Foundation discovered that, while many features of the water system are uniquely Californian, strategies for building knowledge, pursuing solutions, and engaging funders are relevant to water systems across the nation and the world.

FOUNDATION GRANTS BY WATER PROGRAM STRATEGY, 2009-2020

Building scientific knowledge to improve decision-making $\$ 50$ million

Pursuing integrated water solutions, including regional demonstrations $\$ 57$ million

Engaging more funders in water issues $\$ 12$ million

Other

\$11 million

TOTAL

\$130 MILLION 


\section{Building scientific knowledge}

California is home to many impressive research institutions with deep knowledge regarding natural resources and their use. In general, however, these institutions are organized for scientific pursuit, and academic incentives can create silos and competition that hamper effective policy and practice. The Foundation responded to these realities by awarding grants to accelerate the creation and transfer of knowledge among researchers, policymakers, and practitioners - with a goal of ensuring that science informs water management decisions. The Foundation structured its support with the intent to work across institutions and strengthen the relationships between the research community and policy audiences. With Foundation funding, grantees:

- Created governance bodies that could guide and inform research agendas without compromising the integrity of the research produced

- Hosted recurring workshops with key stakeholders to gain sustained input and insight from practitioners and other involved parties

- Expanded communications capacity to support more active outreach to core audiences, including engaging the press

- Incentivized new partnerships across research institutions, technology companies, and nonprofit organizations

Together, these strategies helped ensure that research informing water decision-making was timely, relevant, and actionable. Dozens of grantees participated and contributed to significant progress in this realm. Their efforts were interconnected, helping break down barriers and elevate the importance and usage of quality data. Examples include:

> UC Davis Center for Watershed Sciences. In 2012, the Foundation awarded the UC Davis Center for Watershed Sciences a multi-year grant to expand core staff capacity and leadership development, expand the development of analytical capabilities (i.e., data and models), and increase collaborations with academic partners, state and public agencies, nonprofits, and journalists.

> Public Policy Institute of California's Water Policy Center. In 2014, the Foundation supported the launch of the PPIC Water Policy Center. Since then, the Center has fostered a diverse and robust research network, continually produced timely and accessible research products (over 100 through 2019), and built its organizational capacity and brand. The Center is widely recognized in media outlets including the LA Times and the NYTimes.

> Stanford Water in the West. In 2010, the Foundation awarded Stanford University's Water in the West program a multi-year grant to expand core staff capacity, develop research to inform sustainable groundwater research, and develop and inform approaches to improve urban water management.

> The Nature Conservancy's Water Program. In 2015, the Foundation awarded the Nature Conservancy a multi-year grant to engage in projects related to groundwater, storage, flows, and drought - with a focus on developing analytical tools to help establish statewide freshwater species priorities and understand habitat and water flow needs. 
> OpenET. In 2016, the Foundation supported the launch of OpenET. This web application combines Google's computing power, data from a suite of NASA satellites as well as weather stations, and decades of research by the scientific community to make data about agricultural water use widely accessible. This user-friendly platform is due to launch in 2021 in California and many other western states, with plans for expansion far beyond this geography. It will fill one of the biggest information gaps in water and create a public, shared basis for decision-making.

> Internet of Water and California Water Data Consortium. In 2016, the Foundation invested in development of the Internet of Water, a network of communities and institutions to facilitate the opening, sharing, and integration of water data and information. In 2019, the Foundation supported the launch of the California Water Data Consortium, a nonprofit organization dedicated to helping California make data-informed decisions about water in the face of climate change and other pressures on water resources.

\section{Pursuing integrated solutions}

Many of California's water challenges are the result of fragmentation and long-term, deeply rooted conflict. Enduring solutions require interest groups to transcend any one region, perspective, or issue and work together. The Foundation invested in the pursuit of policies that promote integration, in part by demonstrating solutions at a regional scale. Program efforts focused on activating leadership, developing partnerships, supporting coalitions, and amplifying community voice. With Foundation support, grantees:

- Advanced new narratives and messaging platforms

- Brokered solutions with diverse groups of stakeholders

- Supported leaders through professional development and network engagement

- Engaged communities in local, regional, and statewide decisions about water

Highlights include:

> The Water Foundation. In 2009, the Foundation helped launch an initiative that would grow to become the Water Foundation, a public foundation that focuses on safe water for people, freshwater ecosystem restoration, and climate resilience. The Water Foundation and its partners have advanced several victories for improved water management in California, including the Sustainable Groundwater Management Act, the Open and Transparent Water Data Act, Los Angeles County's Safe Clean Water Program, and the Safe and Affordable Drinking Water Fund.

> Water Solutions Network. In 2017, the Foundation supported creation of the Water Solutions Network. This initiative was chartered to equip rising water leaders from across sectors with the skills, knowledge, and relationships to go beyond business as usual - forging new collaborations and championing solutions for a sustainable, equitable water future. Through collaborative learning and professional contact, the Water Solutions Network nurtures connections and builds abilities that enable diverse leaders to join together and address pressing water challenges in California regions.

\footnotetext{
* The Foundation believed that policy plays an important role in systemic change and that advocacy is a key strategic tool for influencing policy. To this end, the Foundation supported organizations that engage in issue-based policy and advocacy efforts, including raising awareness, building networks and coalitions, nurturing champions, conducting research, etc.

The Foundation did not earmark funds for lobbying activities as defined by the Internal Revenue Code and applicable Treasury Regulations, nor for reportable lobbying activities as defined by the California Political Reform Act or the federal Lobbying Disclosure Act.
} 
> Water Hub. In 2018, the Foundation awarded a multi-year grant to strengthen strategic communications within the water sector through the Water Hub at Climate Nexus. The Water Hub helps ensure that underrepresented voices are heard through media, incorporating perspectives that can expand the reach and resonance of press coverage. The Water Hub coordinates closely with nonprofits and other partners to develop the strategy, narratives, and spokespeople to support shared goals.

> San Joaquin Valley Health Fund. In 2019, the Foundation awarded a grant to the San Joaquin Valley Health Fund Water Cluster alongside support for the Water Foundation to ensure that community members are engaged in land and water management decisions in the Valley. This work helps raise up local community voices as an important source for improving implementation of the Sustainable Groundwater Management Act and the Safe and Affordable Drinking Water Act.

\section{Engaging more funders}

The Foundation dedicated financial resources and staff time to raise awareness about freshwater challenges and solutions and engage other funders in water issues. The Foundation partnered with grantmakers who self-identified as water funders as well as with those who did not consider themselves to be water funders but worked on water-related issues such as climate, health, species conservation, land use, and civic engagement.

With funders focused on water, the Foundation collaborated to identify and support programs that transcended any one geographic area or strategy. In concert, these partners also created a common language and described approaches that facilitated entry of new funders to the field - including inviting participation at different levels of investment and scale.

With funders dedicated to other issues that involve water, the Foundation offered guidance and examples that informed ways that water could be addressed within their respective priorities. The Foundation avoided asking these grantmakers to declare water as a focus; rather, staff sought to support grantmakers in elevating attention to water within their current program portfolios. This approach allows each grantmaker to better understand the importance of funding water in relation to their own priorities - e.g., seeing and addressing how water intersects with health, housing, or education - and also increases the probability of their continued support for water in the future.

Major efforts to attract water funding are summarized as follows:

> Water Funder Initiative. In 2014, the Foundation partnered with the Walton Family Foundation to launch the Water Funder Initiative, an effort to identify and attract philanthropic funding for the most promising solutions to U.S. water problems, starting in the American West. That partnership matured into the Water Funder Initiative - a collaboration dedicated to identifying and activating water solutions throughout the U.S. via strategic philanthropic investments. The Initiative now includes the Gordon and Betty Moore Foundation, the Gates Family Foundation, William and Flora Hewlett Foundation, Lyda Hill Philanthropies, Cynthia and George Mitchell Foundation, the Pisces Foundation, Carroll Petrie Foundation, and the Laural Foundation.

> Smart Growth California. The Foundation invested in Smart Growth California, a group of funders that share a focus on geography rather than a single issue. Foundation staff served on the statewide steering committee and also helped launch a new San Joaquin Valley Funders Group. 
> Community Foundation Water Initiative. The Foundation partnered with a cohort of five community foundations (based in Los Angeles, the Central Valley, San Diego, San Francisco, and Silicon Valley) to elevate their individual and collective work on water issues. The Foundation encouraged these local leaders to incorporate approaches for water quality, water management, or related topics into their already established strategies for public health, climate, or economic growth. Through this Initiative, community foundations built philanthropic expertise to advance solutions to regional water issues.

\section{IMPACT}

The Foundation set its goals broadly and trusted capable grantees to bring their insight, capability, and passion to advance change. These grantee organizations, together with the Foundation and its funding partners, achieved results that were interrelated and hold genuine potential to be enduring in a number of areas vital to California:

Flood Risk and Ecosystems. California is a place that floods and experiences droughts, at times one right after the other. As the climate continues to change, these weather events are more sudden and intense. In 2012, the Central Valley Flood Protection Board unanimously voted to adopt the Central Valley Flood Protection Plan. The Plan incorporates ecosystem goals and provides a comprehensive framework for systemwide flood management and flood risk reduction in the Sacramento and San Joaquin River Basins.

Groundwater Reform. California relies on groundwater for between $40 \%$ and $70 \%$ of its water supply, yet it was the last of the western states to regulate groundwater. In 2014, California passed the Sustainable Groundwater Management Act, landmark legislation that establishes a statewide regulatory framework for managing groundwater resources. The Act provides for local management of groundwater basins while giving the State Water Resources Control Board the authority to intervene if local agencies fail to take action.

Open Data and Information. California has been described as data rich and information poor. In response to the state's droughts, California passed the Open and Transparent Water Data Act (AB1755), and launched partnerships including OpenET, the Internet of Water, and the California Water Data Consortium. These new structures combine to make public data more accessible and useful. As a result, high-quality water data is becoming more available, establishing a shared basis for decision-making and boosting coordination across institutions.

Stormwater and Urban Resilience. Urban runoff is the leading source of surface water pollution for Los Angeles County, one of the world's largest metropolitan economies. Polluted runoff not only harms aquatic life, it poses serious human health risks. Solutions that reduce stormwater pollution, increase the area's local water supply, and provide other environmental and community and public health benefits exist but they are difficult to finance. In 2018, Los Angeles County voters passed Measure W, creating a special tax for parcels located in the Los Angeles County Flood Control District, which covers the majority of Los Angeles County. This tax supports the County's Safe Clean Water Program and is projected to collect $\$ 300$ million per year to pay for infrastructure and programs to capture, treat, and recycle rainwater. It represents the nation's largest local funding measure for green infrastructure.

"The Foundation took an adaptive approach to water, but with a constancy of purpose, leadership, and hope provided by Steve Bechtel and Laurie Dachs."

- JUDE LASPA, BOARD OF DIRECTORS 
Drinking Water Quality. Today, one million Californians lack reliable access to safe and affordable drinking water. In 2012, the state recognized the human right to water via legislation that did not carry a funding mechanism. In 2019, Governor Gavin Newsom signed SB 200, creating the Safe and Affordable Drinking Water Fund. This is the first legislation that specifically targets the challenges that disadvantaged communities face regarding drinking water; it provides $\$ 130$ million for solutions, per year, until 2030. With this Fund, California became the first state to ratify the United Nation's "Human Right to Water" Resolution and to support its successful implementation.

Philanthropic Campaign for Water. Despite the importance of water to California and the American West, there has historically been a lack of significant philanthropic support for improving freshwater systems. In 2014, the S. D. Bechtel, Jr. Foundation supported the launch of the Water Funder Initiative to attract philanthropic resources for the most promising water solutions. Since the inception of the Initiative, the Water Funder Initiative team has coordinated and aligned more than $\$ 345$ million in philanthropic support for water solutions, including $\$ 80$ million in new philanthropic funding.

\section{AMPLIFIED INVESTMENT}

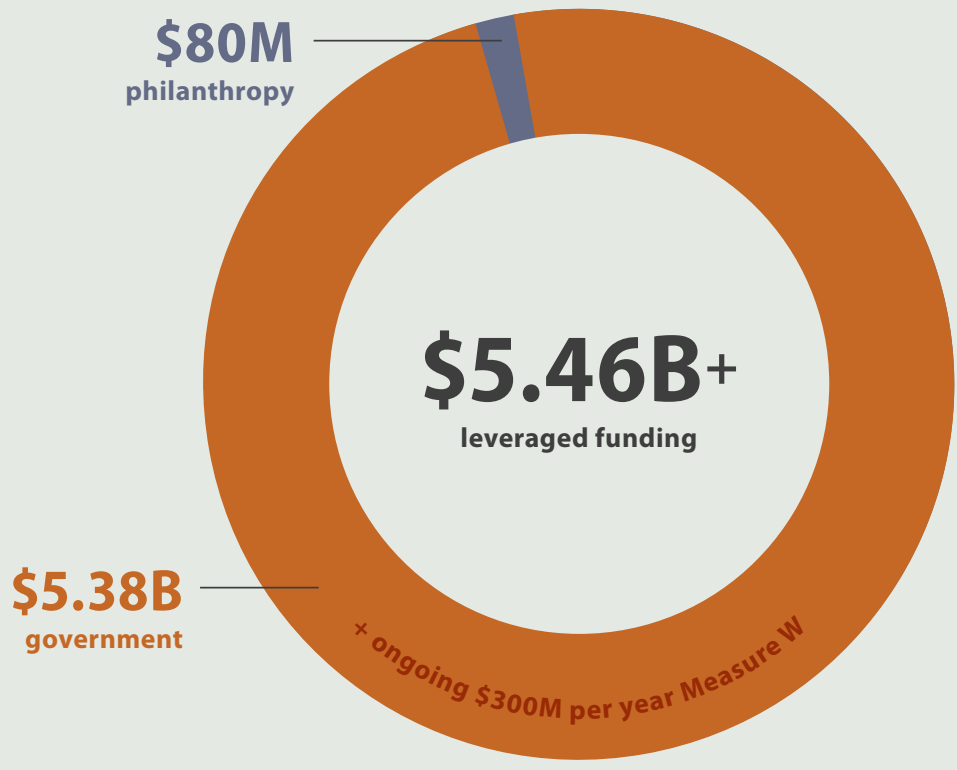

\begin{abstract}
Grantees and other partners played key roles in bringing forward new sources of financial support for water solutions, multiplying the dollars invested by the Foundation more than $\mathbf{4 0}$-fold.
\end{abstract}

Philanthropy

Water Funder Initiative (through 2020)

Government

Safe and Affordable Drinking Water Act

(\$130M per year for ten years)

Measure W (\$300M per year in perpetuity;

first ten years included in total reported here)

Central Valley Flood Protection Plan

$\$ 690 \mathrm{M}$

Sustainable Ground Water Management Act

$\$ 390 M$

\section{Corporate}

Google in-kind services supporting OpenET 


\section{WATER PROGRAM TAKEAWAYS}

The Foundation's multi-year, interconnected grants to support a sustainable water future in California yielded lessons, recommendations, and a perspective on the future. These takeaways from Environment Program staff are offered in hopes they may be helpful to funders, policymakers, and organizations seeking durable results.

\section{Lessons learned}

1. Flexible, multi-year funding matters. Grantees operated in an inherently dynamic context, continually responding to the hydrologic and political realities of California. Many of the Foundation's two-year initiatives became five-year initiatives because the work was so complex. Also, some ten-year initiatives became two-year initiatives because the drought dramatically accelerated public interest and political will to address sweeping change. The Foundation worked closely with grantees to build their core capacities, enhance their resilience, and support their ability to pivot and create impact as windows of opportunity opened.

2. Supporting improved policy can result in large-scale change - and requires implementation resources. The Sustainable Groundwater Management Act has been celebrated as a significant policy win that can have a lasting impact across California. However, the promise of this reform can only be realized if the law is implemented with fidelity. The Foundation provided additional, significant funding after the Act was passed - including support for community engagement in state and local decision-making processes as well as communications, technical assistance, and coordination of networks that are leading implementation. Los Angeles County's Measure W (now the LA County Safe Clean Water Program) and the California Safe and Affordable Drinking Water Fund (now the Safe Affordable Funding for Equity and Resilience Program) similarly require ongoing financial support for successful implementation.

3. Intermediaries add value. Early in its spend down, the Foundation helped build an intermediary, the Water Foundation, to pool and deploy resources to a broad range of partners, including community-based organizations, trade organizations, water districts, and large conservation organizations. In later years, the Environment team broadened its work with intermediaries to include the partnership with community foundations as well as collaboration with the Sierra Health Foundation. These relationships benefited all partners: The Foundation was able to fund a much broader range of projects and organizations than it otherwise could have, and intermediaries grew expertise and contacts in a new program arena.

4. Funder collaboration calls for a distinct mindset and organization-wide involvement. The Foundation decided that funder collaboration was integral to its aspirations for enduring progress on water issues. Collaborative grantmaking was named and treated as a core strategy - not a tactic, addon, or side effort - from the outset of the water program. Flexible resources were earmarked to support engagement with other funders and co-investment in shared priorities. Experience showed that making collaboration part of everyone's job elevated the approach in practice. When trustees, presidents, and program directors as well as communications and evaluation staff from collaborating organizations joined in convenings and meetings, it brought energy and excitement that encouraged existing partners to do more, and attracted new funders to join in water grantmaking and partnerships. 


\section{Recommendations}

1. Take a systems approach to change. A secure water future requires holistic solutions that incorporate understanding systems of hydrology and water infrastructure along with the systems of people, institutions, laws, incentives, and culture that influence how water is managed. The Foundation's experience points to human dynamics as a crucial element in this equation. These dynamics, sometimes hidden beneath the technical language and culture of water management, play a central role in conflict and reconciliation. Funders should consider power dynamics, equity, and inclusion as they approach their work.

2. Invest in organizational capacity early, before moments of crisis and opportunity. The Foundation typically supported program grantees with several years of funding for capacity building. It anticipated that water organizations would need to accelerate or change course at key moments and invested in their abilities to do so. For example, the Water Foundation quickly responded to California's historic drought with media strategies that contributed to the passage of the Sustainable Groundwater Management Act of 2014. In 2020, the Water Hub is tapping into a wave of media interest and advocacy to spotlight how COVID-19 is harming water access and affordability for the Navajo Nation and other under-served populations.

3. Support trust building as integral to progress. Myths and misinformation surround water management, and the Foundation funded the slow, deliberate work required to create trust among stakeholders in water solutions. Staff of the Public Policy Institute of California engaged in extensive local outreach and relationship building at the outset of new efforts in the San Joaquin Valley. These steps enabled constructive conversation and collaboration, and created a ready audience for publication of research findings. Similarly, the OpenET team worked closely with stakeholders across California and the American West from project inception. New connections set the stage for gathering critical input on design of the OpenET platform; responding to those inputs in turn built trust within the agricultural community and anticipation for the launch of OpenET.

4. Partner with other funders. No one philanthropy can take on everything in the expansive water arena; joining with others can help each grantmaker accomplish more that it could envision alone. The advantages go well beyond increasing the amount of money directed to projects and initiatives. Collaboration can help introduce new opportunities as well as shine a light on the strengths and limitations of any individual approach. Peer interactions help funders clarify program assumptions, critically examine strategies, and strengthen approaches. Funder collaboration is not always easy, but it is essential to impact.

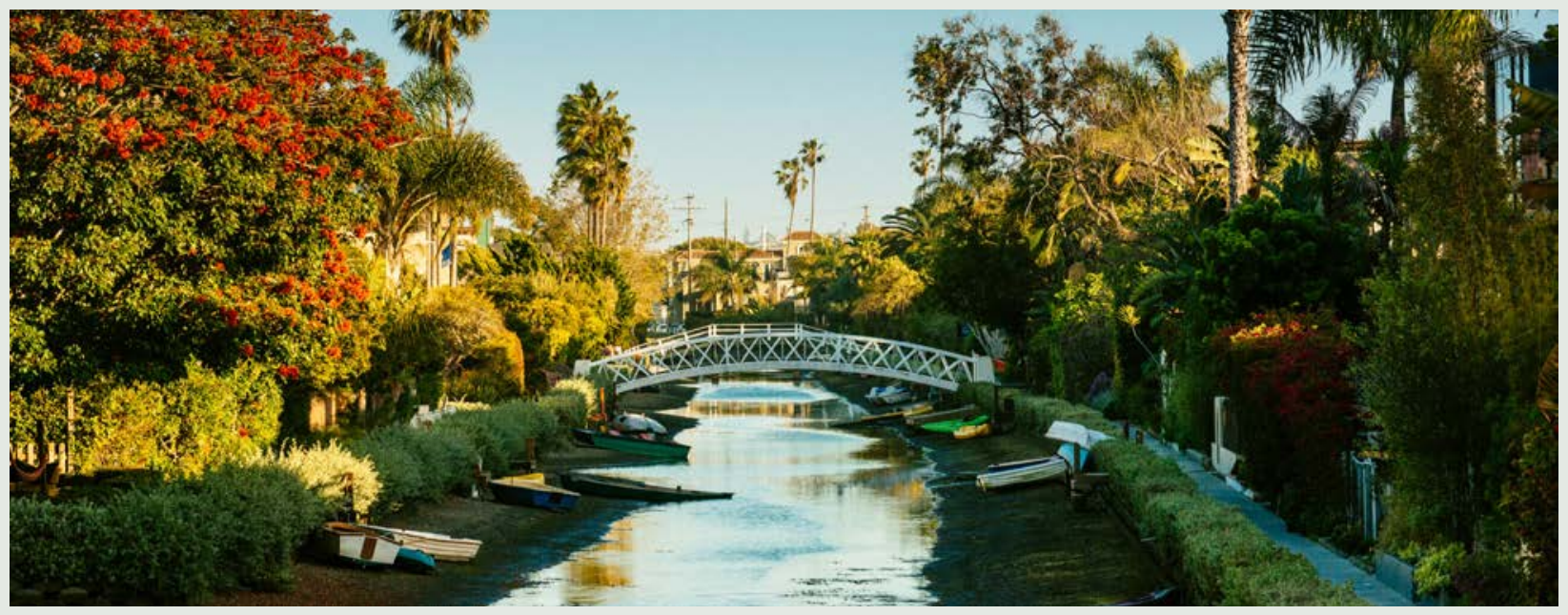




\section{LOOKING AHEAD}

- Water requires integration. California, and the world, are grappling with a pandemic, severe climate impacts, a recession, and racial injustice. Water is connected to each issue, and the field will need to find ways to address these challenges in an integrated fashion. Success will require unprecedented collaboration, sustained resources, and humility. Grantmakers can no longer work in isolation, provide episodic support, and hoard power - all must regularly examine and improve the way philanthropy operates, because there is no time to waste.

- Leadership development is a systems intervention. Policy wins like the Sustainable Groundwater Management Act, Measure W, and the Safe and Affordable Drinking Water Fund are only effective if there is sustained support for leaders who can guide implementation. Future policy wins will only be possible through authentic, diverse, cross-sector partnerships. Funders can respond to these realities by supporting and learning from a range of leadership development programs that uplift community voice and build the power of previously marginalized groups.

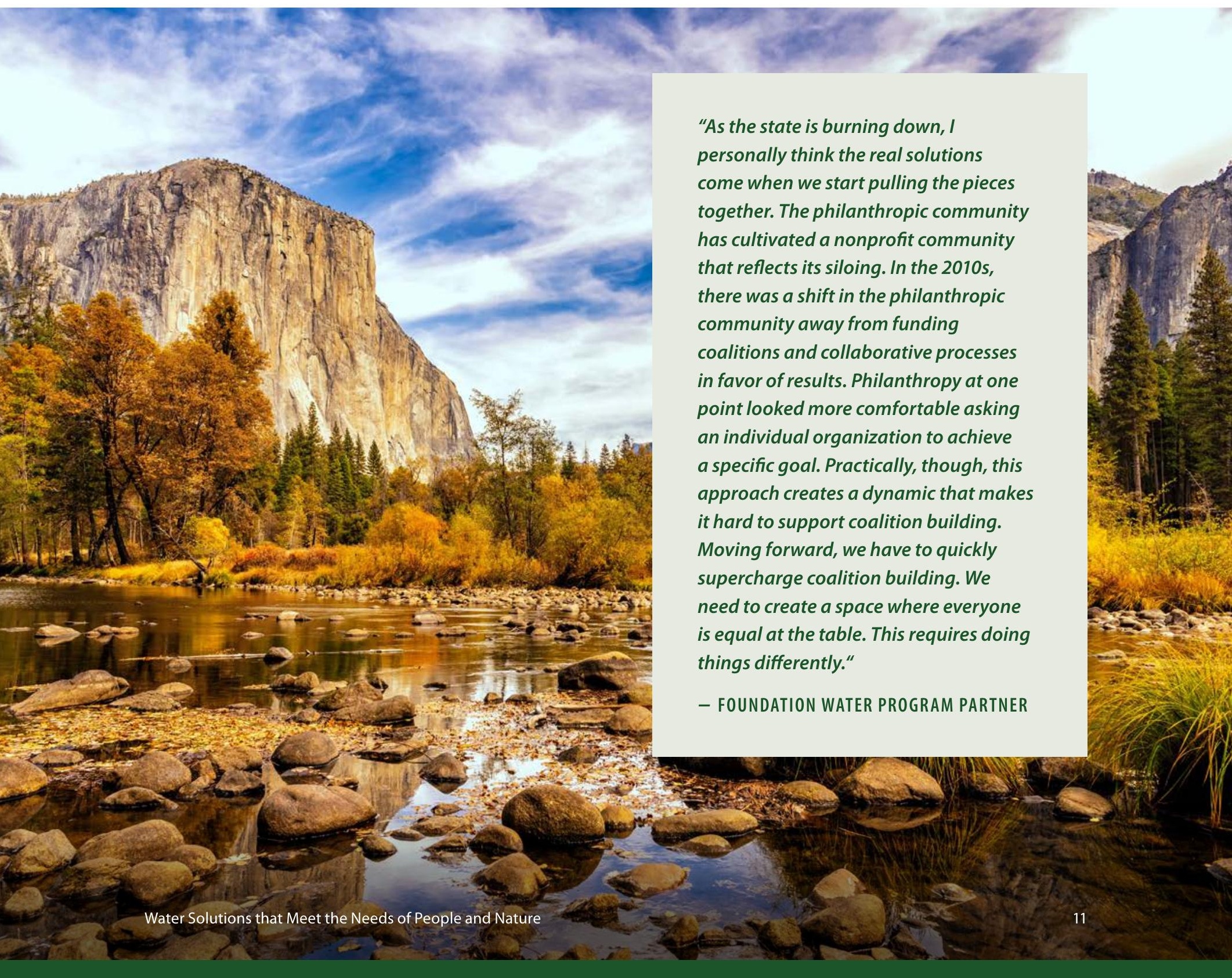




\section{PRODUCTIVE COLLABORATIONS}

The Foundation worked in close collaboration with grantees and many others in the field of water management. The Foundation also benefited from relationships and shared program efforts with a variety of peer funders. The list of colleague organizations is long, and all are deeply valued. Here are just a few examples that may be illustrative to others considering or conducting joint investments.

- Partnering with the Pisces Foundation led the Foundation to broaden its focus, expanding its initial emphasis on water supply to include support for water quality.

- Partnering with the Walton Family Foundation caused the Foundation to address water as an issue that transcended California's borders and involved the American West.

- Partnering with The California Endowment inspired the Foundation to focus on local governance structures and power dynamics as crucial to change in water management.

- Partnering with community foundations in Los Angeles, the Central Valley, San Diego, San Francisco, and Silicon Valley allowed the Foundation to support work that was tailored to local context and tied to climate, housing, and land use.

The Foundation also admired and appreciated the skillful work done by entities and leaders who bring funders together and support collaboration. This group included the Water Funder Initiative, Smart Growth California, and the Water Foundation.

\section{READ MORE}

Managing California's Water: From Conflict to Resolution (2011), Public Policy Institute of California

California's Water: Paying for Water (2018), Public Policy Institute of California

Water and the Future of the San Joaquin Valley (2019), Public Policy Institute of California

Toward Water Sustainability: A Blueprint for Philanthropy (2016), Water Funder Initiative

Internet of Water: Sharing and Integrating Water Data for Sustainability (2017), The Aspen Institute

Environment Program snapshot on capacity building (2020), S. D. Bechtel, Jr. Foundation

Chapter 3, Sooner Rather than Later: The S. D. Bechtel Spend-Down Series (2020); includes information on the Environment Program as well as the Foundation's overarching approaches to capacity building 